\title{
Performance Horse Veterinary Ethics
}

\section{Gustafson $\mathbf{S}^{*}$}

DVM, 918 South Church Avenue, Bozeman, Montana

*Corresponding Author: Gustafson S, DVM, 918 South Church Avenue, Bozeman, Montana.

DOI: $10.31080 /$ ASVS.2020.02.0049
Received: February 07, 2020

Published: February 18, 2020

(C) All rights are reserved by Gustafson S.
Appreciation of the evolved nature and behavior of horses provides the foundation for the ethical veterinary care of equine athletes. The establishment of a veterinary patient client relationship (VCPR) is instrumental in providing ethical care for the competition horse. Ethical veterinary practice supports the horse's longterm health and welfare interests while avoiding pharmaceutical intervention in the days and weeks before competition.

Horses evolved as social grazers of the plains, moving and grazing in a mutually connected and constantly communicative fashion on a near-constant basis. Contemporary equine health and prosperity remains dependent on providing an acceptable degree of this near-constant movement, foraging, and socialization. When horses are confined to fulfill convenience and performance interests, the horse's natural preferences need be re-created to a suitable degree to avoid exceeding the adaptability of the horse. As the adaptability of the horse is exceeded, welfare is diminished and the need for medical intervention to remedy behavioral, health, and soundness deficiencies is intensified. Contemporary practices regularly exceed the competition horse's adaptability, resulting in the need for extensive veterinary intervention to sustain health and remedy training and competition injuries [1].

The more medical care and pharmaceutical intervention required to sustain any population of animals the lower the population's welfare [2]. Ethical veterinary care supports the horse's best welfare interests, as well as the safety of the horse's riders and drivers. Medical intervention of the equine athlete should be avoided in the weeks, days, and hours before competition, as precompetition medication is associated with increased catastrophic injury vulnerability as a result of the diminished welfare it perpetuates [3]. To properly support the health and welfare of equine athletes, the practitioner must be familiar with their patients both inherently and individually. Socialization, constant foraging, and abundant daily locomotion are the long-evolved requirements to promote and sustain optimal soundness, behavioural health, performance, and healing in competition horses.
Healthy horses function and perform more consistently and predictably in an unmedicated state. Contemporary pre-competition medication practices remove the horse's ability to protect their health and sustain soundness by masking pain and suppressing symptomology. Horses who require medication to alleviate medical conditions in order to compete are rendered vulnerable to injury and physical and behavioural dysfunction imperiling the safety of both horse and horseperson. Horses requiring medication to compete are not fit to compete safely. Horses and horse folk are best served to compete free of short-term pre-competition pharmaceutical influence. Infirmities require appropriate medical care and rehabilitation before competition is considered and resumed, rather than pre- competition medication to allay active medical problems. The equine practitioner should focus on post- performance evaluations and necessary therapies to sustain horse health on a enduring basis. An emphasis on fulfilling the medical, physical, and behavioural needs of the horse to prepare for the future competitions is the essence of ethical veterinary care of the competition horse. Pre-competition medication practices that replace or supplant appropriate health care are not in accord AVMA Principles of Veterinary Ethics [4].

For human entertainment, convenience, and revenue, horses are bred, isolated, stabled, conditioned and medicated to perform competitively. Contemporary pre-competition medication practices are often at the expense of the horse's health, safety, and welfare. Many current medication practices violate the AVMA Principles of Veterinary Ethics, specifically the clause that states a veterinarian shall provide veterinary medical care under the terms of a veterinarian-client-patient relationship (VCPR).

The AVMA Principles of Veterinary Ethics state that it is unethical for veterinarians to medicate horses without a VCPR. Precompetition pharmaceutical interventions to remedy insufficient attention and preparation for the horse's long-evolved health requirements are seldom in the best interest of the horse. The medical and pharmaceutical practices which support equine competitive 
pursuits should be designed to enhance the health and soundness of the horse on a long term basis and should not be intended to enhance performance or permit training on infirm legs.

Pre-competition pharmaceutical intervention has been demonstrated to have an overall negative affect on the health and welfare of competitive horse populations. Where horses are allowed to be permissively medicated with and without a VCPR, injuries and catastrophic injuries are more prevalent, as are jockey injuries. Horses are best served to be properly prepared to compete in a natural non- medicated state. Pharmaceutical intervention of the equine athlete should be avoided during training and in the weeks before competition, as pharmaceutical intervention impairs the innate pain barrier while increasing musculoskeletal fragility. Intense and widespread pre-competition medication practices correlate with catastrophic injury vulnerability and diminished welfare [5].

Equine athletic pursuits have historically been designed to measure the natural ability of horses and the trainer's ability to bring out the horses' natural ability. Performance enhancing drugs devalue and debase competitive achievements. Equine competition was designed to measure the natural abilities of horses, with trainers and riders honing those natural abilities. Horse racing was never intended to measure medicated ability, thus maintaining genetic integrity of the breed [6]. Pharmaceutical scrims can impair horses for generations. To suppress a condition that is induced by low welfare is unacceptable. It is imperative in animal sensitive societies that the welfare and veterinary care of the horse take precedence over economic human interests. Horses are born to socialize, communicate, locomote, move about, graze and masticate on a near-constant basis. For behavioral and physical integrity, these preferences need to be re-created to an acceptable degree in the competition stable. The ethical practice of veterinary medicine includes providing clients with the guidance to provide appropriate husbandry, nutrition, conditioning, medical management, and behavioural fulfillment of their equine athletes. Medicating and suppressing injuries with the intent to continue training to later prevail in racing constitutes the unethical and illegal practice of veterinary medicine. Furosemide is a performance enhancing drug, masking agent, and metabolic alkalinizer, and as such is forbidden in racing jurisdictions worldwide, where racing is consequently safer for horses and jockeys.

Equine welfare is best supported when horses are properly prepared, physically and mentally sound, and fit to perform in an unmedicated state. Physically or behaviourally impaired horses who require medication to compete should not compete until they are able to compete without pre-competition pharmaceutical in- tervention. All sensation, behaviour, and proprioception should remain physiologically normal. Sensation and cognitive awareness should not be suppressed with pre-competition medication. This includes the use of sedatives, stimulants, and pain relievers of all sorts. Treatments should not interfere with functional physiology.

Sound horses properly prepared for competition have little need for pre-competition medication. Unsound or behaviorally dysfunctional horses should be medically and behaviorally rehabilitated in a fashion that restores soundness before training and competition are resumed. Medication is for infirm horses, and infirm horses should not compete. Horses who require medication to compete become increasingly unfit to compete safely. Rather than therapeutic intent, many pre-competition medication practices have become performance enhancing at the expense health and welfare of horse and rider.

It has been demonstrated through time that horses and their riders are best served to compete medication free. As a result, antidoping laws have been established by all agencies that regulate equine competition. Veterinarians are required by both ethics and law to follow these regulations.

Horseracing statistics support that the less medication horses receive the more favorably and safely horses compete [5].

The safety of the competition horse is dependent on unimpaired neurological functioning. Unimpaired sensation and cognitive ability are necessary for a horse to compete safely and fairly. Any medications or procedures which negate or diminish sensation and awareness in the horse impair the ability of the horse to compete safely [7].

The safety, longevity, and durability of the equine patient should considered before short term pre- competition medical solutions are implemented. Familiarity of the patient includes familiarity with stabling, genetics, behavior, and husbandry of the patient. Many if not most medical conditions are a result of human mismanagement of equine stabling and conditioning. When the adaptability is exceeded, horses become unsound. Assessment of stabling conditions and athletic preparation practices are essential components of ethical equine care. Healing must be allowed to progress before competition and training are resumed. Client education is essential to create a husbandry situation conducive to equine healing. Restoration strategies that recreate the horse's social grazing and locomotion preferences facilitate and potentiate horse healing. Appropriate healing of many equine maladies is encouraged when the veterinarian provides appropriate medical care and carefully 
facilitates a scenario to provide the horse with appropriate physical rehabilitation and behavioural fulfillment.

Despite domestication and selective breeding for docility and captivity, horse health remains dependent on locomotion. Locomotion is inherent to digestion, to respiration, to metabolism, to hoof health and function, to joint health, to bone health and durability, to resistance to limb failure, and to behavioral fulfillment. An interdependence exists between horse health and locomotion. Horses evolved to be near- constant walkers and grazers, depending on perpetual motion to sustain health of all systems. Horses did not evolve to be confined in stalls and stables, but to move on a continuous basis. Pulmonary health is dependent on abundant daily locomotion. Deprivation of adequate locomotion results pulmonary deterioration, resulting in an abnormal incidence of EIPH. By suppressing EIPH, Lasix perpetuates the substandard American training horsemanship that causes EIPH.

When horses are deprived of adequate and abundant locomotion, they develop strategies and unwelcome behaviors to keep themselves and their jaws in motion, as is their essential nature. Horses deprived of friends, forage, and locomotion are at risk to develop stereotypies to provide themselves with the movement they need to survive. The more stereotypies present in a population of equine athletes, the lower their welfare.

No longer is intense medical intervention prior to competition a viable, ethical, or legal approach. It has been demonstrated that the more intensely horses are medicated to compete, the lower their welfare. The more medications required to sustain any population of animals, the further the deviation from their physical and behavioural needs. Rather than pre-race treatments, the ethical approach includes performance of extensive post-competition examinations to address any weaknesses or unsoundness as a result of the performance.

Alternatives to precompetition medication with non steroidal anti-inflammatory medication and steroids include fulfillment of the horse's long-evolved nature. Musculoskeletal soundness is attained by proper breeding, development, husbandry, and conditioning practices. Management of exercise induced pulmonary hemorrhage is achieved by specific lifetime daily development of the horse's pulmonary and cardiac function. As well, unwelcome and unsafe competition behaviors are best managed by fulfillment of the horse's inherent behavioral needs, which include abundant daily socialization, locomotion, and grazing [8].

\section{Bibliography}

1. Zambruno Teresita. "Epidemiological investigations of equine welfare at OSAF jurisdiction racecourses”. Thesis (2017).

2. Appleby M., et al. "Animal Welfare". CABI, Second edition (2011).

3. Slifer., et al. "A Review of Therapeutic Drugs Used for Doping of Race Horses: NSAIDs, Acepromazine, and Furosemide". Thesis (2017).

4. The AVMA. Principles of Veterinary Ethics.

5. Kentucky Horseracing Commission Raceday Medication Transcript (2011).

6. Magner D. Magner's Classic Encyclopedia of the Horse Edison, New Jersey: Castle Books (2004).

7. Furr M and Reed S. Equine Neurology; Wiley-Blackwell (2007).

8. Waran N., et al. Training Methods and Horse Welfare in Waran $\mathrm{N}$, ed The Welfare of Horses, Dordrecht, The Netherlands: Kluwer Academic Publishers (2002): 151-180.

\section{Assets from publication with us}

- Prompt Acknowledgement after receiving the article

- Thorough Double blinded peer review

- Rapid Publication

- Issue of Publication Certificate

- High visibility of your Published work

Website: www.actascientific.com/

Submit Article: www.actascientific.com/submission.php

Email us: editor@actascientific.com

Contact us: +919182824667 